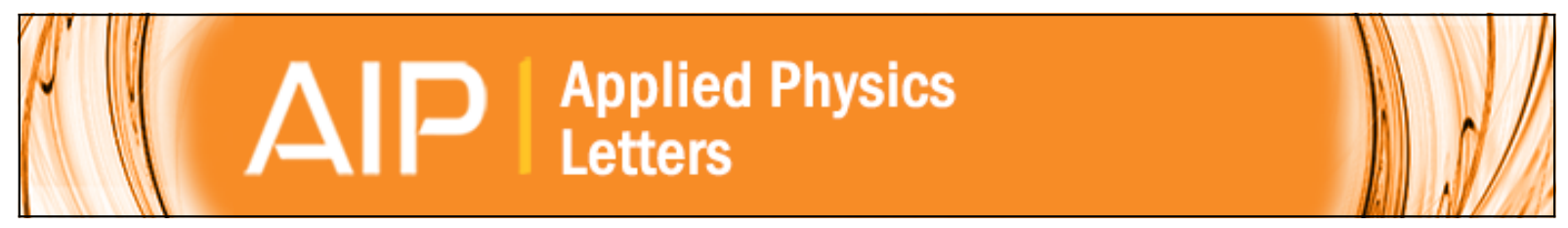

\title{
Ultrafast nonlinearity of antimony polyphosphate glasses
}

E. L. Falcão Filho, C. A. C. Bosco, G. S. Maciel, Cid B. de Araújo, L. H. Acioli, M. Nalin, and Y. Messaddeq

Citation: Applied Physics Letters 83, 1292 (2003); doi: 10.1063/1.1601679

View online: http://dx.doi.org/10.1063/1.1601679

View Table of Contents: http://scitation.aip.org/content/aip/journal/apl/83/7?ver=pdfcov

Published by the AIP Publishing

\section{AlP}

\section{Create a profile. \\ Sign up today!}




\title{
Ultrafast nonlinearity of antimony polyphosphate glasses
}

\author{
E. L. Falcão Filho, C. A. C. Bosco, G. S. Maciel, Cid B. de Araújo, ${ }^{\text {a) }}$ \\ and L. H. Acioli \\ Departamento de Física, Universidade Federal de Pernambuco, 50670-901 Recife, PE, Brazil \\ M. Nalin and Y. Messaddeq \\ Instituto de Química, Universidade do Estado de São Paulo-UNESP, 14800-900 Araraquara, SP, Brazil
}

(Received 8 April 2003; accepted 16 June 2003)

\begin{abstract}
We report on the ultrafast nonlinearity of antimony polyphosphate glasses measured using the Kerr shutter technique. The nonlinear refractive index, $n_{2}$, was $(1.1 \pm 0.2) \times 10^{-14} \mathrm{~cm}^{2} / \mathrm{W}$ at $800 \mathrm{~nm}$, and enhancement of $n_{2}$ by $\approx 80 \%$ was observed by adding $10 \%$ of lead oxide in the glass composition. The full width at half-maximum of the third-order correlation signal was $150 \mathrm{fs}$, which implies a fast response of the samples $(\leqslant 100 \mathrm{fs})$. Nonlinear absorption was negligible in the range of intensities used. (C) 2003 American Institute of Physics. [DOI: 10.1063/1.1601679]
\end{abstract}

Highly nonlinear optical materials are of large interest for applications including optical limiting, all-optical switching, and other current photonic uses. Among the materials available to date, antimony-based glasses are emerging as promising systems for such applications. ${ }^{1-4}$ These glasses present a high refractive index, a large infrared transmission window, and good thermal stability. Antimony oxide $\left(\mathrm{Sb}_{2} \mathrm{O}_{3}\right)$ is the main glass component and is considered as the glass former. Samples of $\mathrm{Sb}_{2} \mathrm{O}_{3}$-based glasses with high optical quality are difficult to obtain, but new methods of preparation have been developed, ${ }^{2,3}$ and good quality samples are now available.

Recently, the nonlinear optical absorption of antimony and lead oxyhalide glasses was studied using laser pulses of $80 \mathrm{ps}$ at $532 \mathrm{~nm} .{ }^{4}$ Large nonlinear absorption coefficients up to $20 \mathrm{~cm} / \mathrm{GW}$ were measured that illustrate the possibility of using these glasses for optical limiting.

In this letter, we demonstrate the use of antimony polyphosphate glasses for operation of an ultrafast optical gate in the near-infrared. The experiments were performed with samples having the following compositions: (sample A) $70 \mathrm{Sb}_{2} \mathrm{O}_{3}-30 \mathrm{Sb}\left(\mathrm{PO}_{3}\right)_{3}$; and (sample B) $70 \mathrm{Sb}_{2} \mathrm{O}_{3}$ $-20 \mathrm{Sb}\left(\mathrm{PO}_{3}\right)_{3}-10 \mathrm{PbO}$.

The antimony glasses were prepared according to the following procedure: $\mathrm{Sb}\left(\mathrm{PO}_{3}\right)_{3}$ was prepared heating ammonium dihydrogen phosphate (analytical grade; purity larger than 99\%) and antimony oxide (spectral grade; purity larger than $99 \%$ ) in a platinum crucible in two stages, the first one at $200{ }^{\circ} \mathrm{C}$ for $2 \mathrm{~h}$ and the second one at $500{ }^{\circ} \mathrm{C}$ for $4 \mathrm{~h}$. The glass synthesis was carried out by melting $\mathrm{Sb}_{2} \mathrm{O}_{3}$ (purity larger than $99 \%$ ) and $\mathrm{Sb}\left(\mathrm{PO}_{3}\right)_{3}$ in glassy carbon crucibles in an electrical furnace for $10 \mathrm{~min}$ at $700-1000{ }^{\circ} \mathrm{C}$ in room atmosphere. The liquid was then cast into a brass mold at $20^{\circ} \mathrm{C}$ and glass samples were obtained after cooling. The characteristic temperatures $T_{g}=320^{\circ} \mathrm{C}$ (glass transition temperature) and $T_{x}=420^{\circ} \mathrm{C}$ (onset of crystallization) were determined by differential scanning calorimetry. X-ray diffraction of the samples shows the typical halo characteristic of

\footnotetext{
a) Author to whom correspondence should be addressed; electronic mail: cid@df.ufpe.br
}

the amorphous state. Further characterization of the samples was made using Raman scattering and nuclear magnetic resonance. More details on the samples preparation are given in Refs. 2 and 3.

Figure 1 shows the absorption spectra of the samples at room temperature, which show a high transparency window for wavelengths larger than $\approx 500 \mathrm{~nm}$. The linear refractive index of the samples was measured using the prism-coupling technique at $633 \mathrm{~nm}$ and the results are presented in Table I.

The nonlinearity of the samples was investigated using an optical Kerr shutter setup, ${ }^{5}$ with the sample placed between crossed polarizers. To perform this time-resolved noncollinear pump-and-probe experiment, a Ti:sapphire laser operating at $800 \mathrm{~nm}$ and delivering 100-fs pulses at $82 \mathrm{MHz}$ was employed. The laser beam was split in two beams with relative intensities of 1:10. The stronger (pump) beam induces a birefringence on the sample; that is a refractive index change $\Delta n(t)=n_{2} I_{\text {pump }}(t)$, where $n_{2}$ is the nonlinear refractive index and $I_{\text {pump }}(t)$ is the pump beam intensity. The probe beam with its polarization set at $45^{\circ}$ with respect to the pump beam is used to investigate the dynamics of the process. A fraction of its intensity leaks out the polarizer analyzer located in front of the photodiode, which allows for heterodyne detection of $\Delta n(t)$. When the pump beam is present, the probe beam polarization is rotated due to the induced birefringence with a dynamical behavior that depends on the material's response time. Consequently, a larger

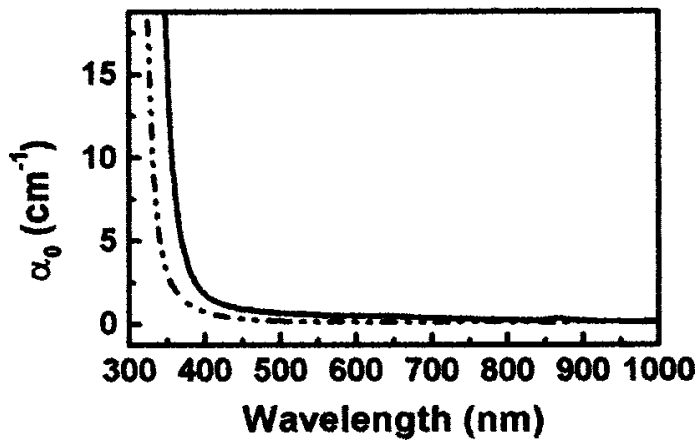

FIG. 1. Absorption coefficient $\alpha_{0}$ of the studied samples. The dashed line (solid line) refers to sample A (sample B). 
TABLE I. Parameters of the samples studied. $n_{0}$ is the linear refractive index measured at $633 \mathrm{~nm}, \alpha_{0}$ is the linear absorption coefficient at $800 \mathrm{~nm}$, $L$ is the sample length, and $n_{2}$ is the effective nonlinear refractive index.

\begin{tabular}{lcccc}
\hline \hline Sample & $n_{0}$ & $\begin{array}{c}\alpha_{0} \\
\left(\mathrm{~cm}^{-1}\right)\end{array}$ & $\begin{array}{c}L \\
(\mathrm{~mm})\end{array}$ & $\begin{array}{c}n_{2} \\
\left(10^{-14} \mathrm{~cm}^{2} / \mathrm{W}\right)\end{array}$ \\
\hline A & 1.906 & 0.150 & 0.65 & $1.1 \pm 0.2$ \\
B & 1.975 & 0.24 & 1.13 & $2.0 \pm 0.4$ \\
\hline \hline
\end{tabular}

fraction of the probe beam intensity reaches the photodiode. A lock-in amplifier provides a temporally averaged signal $S(\tau) \propto\left\langle\Delta n(t)\right.$. $\left.I_{\text {probe }}(t+\tau)\right\rangle$ for each time delay $\tau$ between pump and probe pulses spatially overlapped at the sample position. The signal $S(\tau)$ was monitored by scanning a computer controllable delay line which allows for different values of $\tau$. It is observed that the signal is only present when $\tau$ is smaller than the field's correlation time.

To illustrate the sensitivity of the setup used, we show in Fig. 2(a) the third-order correlation signal for a 1.6-mm-thick slab of fused quartz. A good signal-to-noise ratio is obtained. Figure 2(b) shows the behavior of $S(\tau)$ for the two glass compositions studied, which present much larger nonlinearities than fused quartz. For the assumed hyperbolic secant pulse shape, the symmetric correlation signal width of $155 \mathrm{fs}$ implies that the samples have a response faster than $105 \mathrm{fs}$. This means that the origin of the nonlinearity may be attributed to electronic processes either alone or in combination with other processes whose characteristic times are shorter than $105 \mathrm{fs}$.

Figure 3(a) illustrates the behavior of $S(\tau)$ as a function of the pump laser power, while Fig. 3(b) shows the linear behavior of the signal amplitude versus pump laser power, as expected for a heterodyne Kerr shutter signal.

Variation of the samples' transmittance as a function of
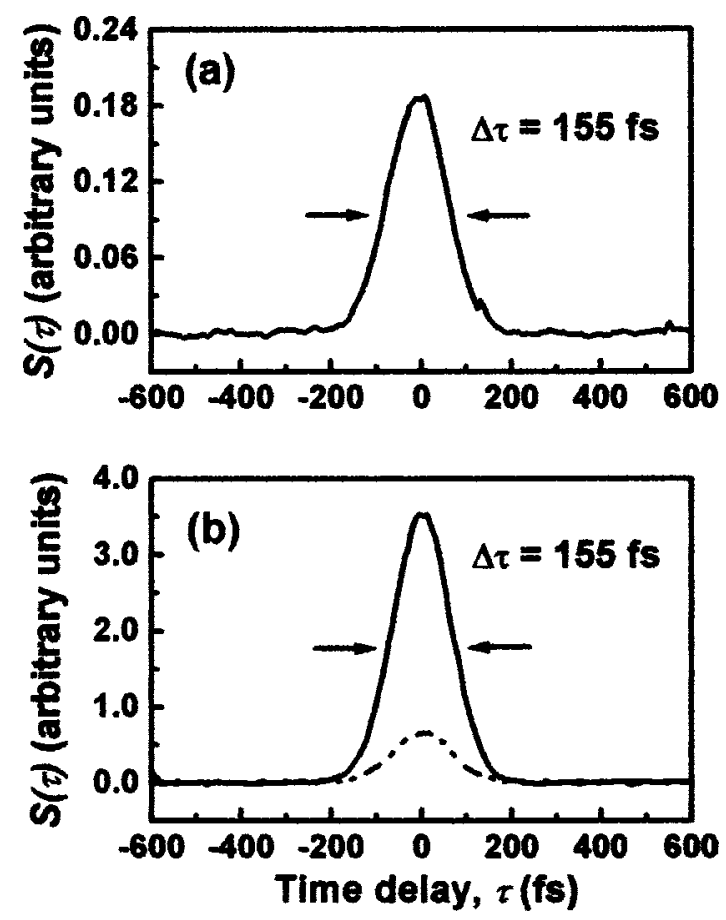

FIG. 2. Kerr shutter signals. (a) Fused quartz: reference sample (length: 1.6 $\mathrm{mm}$ ). (b) Samples studied. The dashed line (solid line) refers to sample A (sample B).
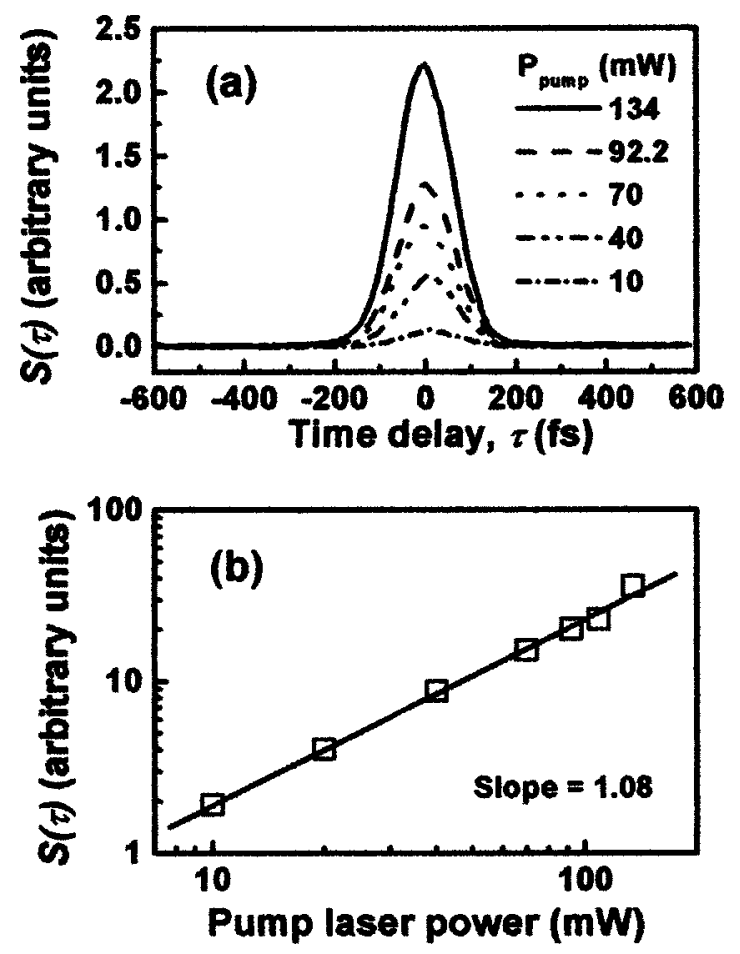

FIG. 3. Dependence of the Kerr shutter signal $S(\tau)$ with the pump laser intensity. (a) Results for sample B for different pump laser powers. (b) Linear dependence of $S(\tau)$ with the incident pump laser power.

the pump beam intensity was not detected in all experiments which implies that the two-photon absorption coefficient is below our detection limit $(<0.01 \mathrm{~cm} / \mathrm{GW})$.

The magnitude of $n_{2}$ is obtained by comparison with the nonlinear refractive index of fused quartz of 2.2 $\times 10^{-16} \mathrm{~cm}^{2} / \mathrm{W}$ (Ref. 6) which was used as a calibration standard. The values of $n_{2}$ for the studied samples are given in Table I. Notice that the result for sample A is fifty times larger than the one corresponding to quartz. This is correlated with the high polarizability of $\mathrm{Sb}^{2+}$ owing to the presence of two $s$-electrons in the external shell. Recalling common features between $\mathrm{Sb}^{2+}$ and $\mathrm{Te}^{4+}$, such as the same electronic structure, very close atomic weight, and a lone pair of $s$-electrons, we expect for the antimony glasses studied here a high nonlinearity, as is observed in $\mathrm{TeO}_{2}$-based glasses. Moreover, we note that sample B, which contains lead oxide, has an $80 \%$ larger nonlinearity than sample A. This result can be attributed to the high polarizability of $\mathrm{Pb}^{2+}$, which also presents a lone pair of $s$-electrons in the external shell, but has larger polarizability than $\mathrm{Sb}^{2+}$.

In summary, we described the characterization of the response time and the value of the nonlinear refractive index of antimony polyphosphate glasses as well as demonstrated its application as an ultrafast Kerr gate. The temporal response observed was limited by the laser pulse duration available but indicates a fast response of the samples. On the other hand, the refractive nonlinearity is high in comparison to other optical glasses commonly studied, ${ }^{7}$ but two-photon absorption is negligible.

Financial support for this work by the Brazilian Conselho Nacional de Desenvolvimento Científico e Tecnológico $(\mathrm{CNPq})$ and Fundação de Amparo à Ciência e Tecnologia do Estado de Pernambuco (FACEPE) is acknowledged. The au- 
thors are also grateful to B. J. P. da Silva for cutting and polishing the samples.

${ }^{1}$ G. Poirier, M. Poulain, and M. Poulain, J. Non-Cryst. Solids 284, 117 (2001).

${ }^{2}$ M. Nalin, M. Poulain, M. Poulain, S. J. L. Ribeiro, and Y. Messaddeq, J. Non-Cryst. Solids 284, 110 (2001).
${ }^{3}$ M. Nalin, Ph.D. Thesis, University of São Paulo State (UNESPAraraquara), 2001.

${ }^{4}$ R. E. de Araujo, C. B. de Araújo, G. Poirier, M. Poulain, and Y. Messaddeq, Appl. Phys. Lett. 81, 4694 (2002).

${ }^{5}$ See for example, Y. R. Shen, The Principles of Nonlinear Optics (Wiley, New York, 1984).

${ }^{6}$ R. DeSalvo, A. A. Said, D. J. Hagan, E. W. Van Stryland, and M. SheikBahae, IEEE J. Quantum Electron. 32, 1324 (1996).

${ }^{7}$ See for instance, M. Yamane and Y. Asahara, Glasses for Photonics (Cambridge University Press, Cambridge, UK, 2000). 